\title{
Conference abstract
}

\section{The Graz Declaration on Disability and Ageing 2006}

\author{
Germain Weber, Dr phil. Professor of Psychology, Faculty of Psychology, University of Vienna, Vienna, Austria
}

Correspondence to: Germain Weber, E-mail: germain.weber@univie.ac.at

\section{Abstract}

Introduction: Traditionally, the fields of ageing and disability have been addressed separately both in terms of research and service structures and systems of care. However, in recent years, public awareness into topics involving ageing and disability-twin-track approachhas been growing and research linking both fields enjoys rising attention.

A twin-track model: Ageing as viewed from the perspective of people with disabilities-those with life-long disabilities as well as those with age-related disabilities - is the main focus of the Graz Declaration of June 2006. Considering international declarations developed separately for the fields of ageing and disability, the Graz Declaration aims at analysing and bridging the rights and responsibilities of these two groups while including the conception of the person with a disability, as expressed in principles such as inclusion, participation, equal opportunities, non-discrimination, and self-determination. The declaration aims at clarifying common variance, and emphasizes the unique requirements and needs of specific groups of older people with disabilities. Besides conceptual and strategic reasons the declaration follows straightforward reasons affecting the life of older people with disabilities directly or indirectly such as bridging the practice models of care of the ageing field with that of the area of intellectual disability, or defining tools to detect commonalities as well as differences between the needs of older people with a life-long disability and those with age-related disabilities.

Conclusion: The Graz Declaration's effect on developing a more coherent support systems aiming at equal opportunities and full citizenship for older people with disabilities in diverse, yet integrated fields such as politics, care, training, research, culture, ethics and economics will be addressed.

\section{Keywords}

disability, ageing, Graz Declaration on Disability and Ageing

Presentation slides available from:

http://www.bridgingknowledge.net/Presentations/Symp4_Weber.pdf 